\title{
Low Deposition Temperature-Induced Changes of the Microstructure and Tribological Property of $\mathrm{WS}_{2}$ Film
}

\author{
Ming Hu ${ }^{1}$, Yi Dong ${ }^{2}$, Yan Wang ${ }^{3}$, Desheng Wang ${ }^{1}$, , Dong Jiang ${ }^{1}$, Yanlong Fu ${ }^{1}$, Lijun Weng ${ }^{1}$, \\ Jiayi Sun ${ }^{1}$ and Xiaoming Gao ${ }^{1, *}$ \\ 1 State Key Laboratory of Solid Lubrication, Lanzhou Institute of Chemical Physics, Chinese Academy of \\ Sciences, Lanzhou 730000, China; hum413@1zb.ac.cn (M.H.); jiangd@licp.cas.cn (D.J.); \\ fyanl@licp.cas.cn (Y.F.); wenglj@licp.cas.cn (L.W.); sunjy@licp.cas.cn (J.S.) \\ 2 Shanghai Aerospace System Engineering Institute, Shanghai 201108, China; bert.dy@126.com \\ 3 China Academy of Space Technology, Beijing 100094, China; yanzi2008hehe@126.com \\ * Correspondence: wangdsh@licp.cas.cn (D.W.); gaoxm@licp.cas.cn (X.G.); Tel.: +86-931-4968-071 (D.W.); \\ +86-931-4968-091 (X.G.)
}

Received: 28 February 2019; Accepted: 27 March 2019; Published: 30 March 2019

\begin{abstract}
Pure $\mathrm{WS}_{2}$ films were prepared by the radio frequency sputtering of a $\mathrm{WS}_{2}$ target with the initial substrate temperature controlled to $-40,-25,0{ }^{\circ} \mathrm{C}$ and room temperature by cooling the holder with liquid nitrogen, respectively. The influence of the substrate temperature on the microstructures and the tribological properties of the prepared films have been evaluated and the wear mechanism of the films was explained. It revealed that with decreasing the substrate temperature, the prepared $\mathrm{WS}_{2}$ film changed from the loose and coarse columnar plate structure for film deposited at room temperature to a much more compact morphology for film deposited at $-40{ }^{\circ} \mathrm{C}$. The $\mathrm{WS}_{2}$ film deposited at low temperature of -40 or $-25{ }^{\circ} \mathrm{C}$ exhibited a long wear life higher than $5.0 \times 10^{5}$ sliding cycles, while this was about $1.5 \times 10^{5}$ cycles for the $\mathrm{WS}_{2}$ deposited at room temperature. The improved tribological properties for the low temperature-deposited film were mainly attributed to the much lower wear rate resulted from the compact structure as well as the sustained and steadily formed transform layer on the counterpart ball.
\end{abstract}

Keywords: tungsten disulfide; low temperature deposition; tribological property; wear life

\section{Introduction}

Sputtered transitional metal dichalcogenide (TMD) coatings, such as $\mathrm{MoS}_{2}$ and $\mathrm{WS}_{2}$, have been extensively investigated and applied as a super low friction lubricating materials for aerospace applications due to their excellent lubrication behavior especially under high vacuum conditions [1-5]. It has been investigated that the microstructure and the chemical composition of the deposited TMD films have a crucial effect on the friction coefficient and the wear life. Typically, the related characterization of the TMD films were controlled mainly by the deposition parameters, such as work pressure, substrate bias and substrate temperature [6-8]. However, the pure TMD films deposited at room temperature or a higher temperature exhibited a growth of the columnar plate structure. The coarse columnar plates constituted TMD films failed early during the friction and showed a very limited lifetime [9-11]. The poor wear resistance and short wear life of pure $\mathrm{MoS}_{2}$ or $\mathrm{WS}_{2}$ coatings limited their service in present and future long-life aerospace applications.

At present, modifying the microstructure by doping the TMD film with other elements or constructing multilayer structures is a conventional way to improve the tribological property of the TMD-based lubricating films It has been reported that the incorporation of metals or non-metallic elements and components into the TMD films helps in constricting a much denser structure and 
reducing the wear rate of the films [12-18]. The multilayer architecture, controlled by alternating the nanometer-thick layer of $\mathrm{MoS}_{2}$ or $\mathrm{WS}_{2}$ and metal or compounds layer, has also been investigated to improve the tribological properties by the adjusting of the film microstructure and stress distribution [19-23]. Other novel designs of the pure TMD films for improving the tribological property were also investigated. It has been reported that the tribological property of the TMD film showed a significant improvement, especially exhibiting a long lubricating life, by depositing the pure TMD films onto the textured substrate or textured coatings [24-27]. The morphology of textured substrate or coating has a great influence on the growth of the pure TMD film and the optimized structure play an advantageous effect to achieve both the low friction coefficient and long wear life. The effect of the substrate temperature, another influence factor for the growth of the film, has long been investigated. However, previous research mainly focused on the effect of substrate temperature higher than room temperature on the microstructure and the friction coefficient of the TMD film [7,27-30]. The TMD film deposition at cryogenic temperature was rarely investigated. Spalvins [30] reported the sputtered $\mathrm{MoS}_{2}$ film deposited at $-195^{\circ} \mathrm{C}$ have no lubricating characteristics due to the amorphous structure while $\mathrm{MoS}_{2}$ film deposited at ambient or high temperature exhibited a well crystallized structure and low friction coefficient. Up to now, very little research has been done on the transitional region of the TMD film deposited at lower substrate temperature than ambient temperature.

In this paper, pure $\mathrm{WS}_{2}$ films were deposited at substrate temperature range from -40 to $20^{\circ} \mathrm{C}$. The purpose of this article is to figure out the changes of the microstructure for the $\mathrm{WS}_{2}$ deposited at different temperatures and to investigate the improvement of the tribological properties as well as the wear mechanism for the low temperature-deposited film.

\section{Experiment}

\subsection{Sample Preparation}

Pure $\mathrm{WS}_{2}$ films were prepared by the radio frequency sputtering of one $\mathrm{WS}_{2}$ target $(76.2 \mathrm{~mm}$ in diameter, $99.9 \%$ in purity) at different low substrate temperatures controlled by a sample holder cooled by liquid nitrogen as illustrated elsewhere [31]. Commercially mechanically polished stainless steel (AISI 440C, $R_{\mathrm{a}} \leq 0.02 \mu \mathrm{m}$ ) and $\mathrm{Si}$ wafer were used as the substrates. Prior to deposition, the vacuum chamber was evacuated to a base pressure of $3.0 \times 10^{-3} \mathrm{~Pa}$, and then the substratesurfaces were $\mathrm{Ar}$ plasma bombarded for $20 \mathrm{~min}$ with a bias voltage of $-600 \mathrm{~V}$ at a pressure of $2.0 \mathrm{~Pa}$. Subsequently, the temperature of the substrate was controlled by cooling the substrate holder with a stable flow rate of liquid nitrogen. Through adjusting the flow rate of the liquid nitrogen, the substrate temperature was controlled to a stable temperature of $-40,-25,0{ }^{\circ} \mathrm{C}$ before the film deposition, respectively. When the substrate temperature was stabilized to the aimed value, the $\mathrm{WS}_{2}$ film was deposited by the radio frequency sputtering of the $\mathrm{WS}_{2}$ target with a power of $300 \mathrm{~W}$ under a working pressure of $2.0 \mathrm{~Pa}$ controlled by the flow rate of Ar with $30 \mathrm{~min}$. The flow rate of the cooled liquid nitrogen remained unchanged during the film deposition while the substrate temperature was spontaneously increased due to the ion bombardment. The $\mathrm{WS}_{2}$ film deposited at room temperature of about $20^{\circ} \mathrm{C}$ was also deposited without the liquid nitrogen cooling while other conditions were not changed. The $\mathrm{WS}_{2}$ films deposited at temperatures of $-40,-25,0{ }^{\circ} \mathrm{C}$ and room temperature were named with $\mathrm{WS}_{2}-40, \mathrm{WS}_{2}-25$, $\mathrm{WS}_{2}-0$ and $\mathrm{WS}_{2}-\mathrm{RT}$, respectively.

\subsection{Film Characterization and Tribological Measurements}

The morphologies of $\mathrm{WS}_{2}$ films deposited at different temperatures were characterized by high-resolution field emission scanning electron microscopy (FE-SEM, Hitachi SU8020, Tokyo, Japan) and a transmission electron microscope (TEM, JEOL 2100F, Tokyo, Japan). The crystal structures of the films were examined with an X-ray diffraction (XRD, X'Pert Pro, PANalytical Co., Almelo, The Netherland; $40 \mathrm{kV}$ ) with $1.54 \AA \mathrm{Cu} \mathrm{K} \alpha$ radiation under an incident beam angle of $3^{\circ}$. The tribological properties of the prepared films were tested on a standard ball-on-disk tribometer 
(WTM-2E, Lanzhou Institute of Chemical Physics, Lanzhou, China) under vacuum $\left(<5.0 \times 10^{-3} \mathrm{~Pa}\right)$ at room temperature. The counterpart was AISI $440 \mathrm{C}$ steel ball of $8 \mathrm{~mm}$ in diameter. The sliding speed was $1000 \mathrm{r} / \mathrm{min}$ with a rotational radius of $8 \mathrm{~mm}$, corresponding to a linear speed of about 0.84 $\mathrm{m} \mathrm{s}^{-1}$, and the normal load was $5 \mathrm{~N}$ corresponding to a maximum Hertz contact stress of 1.0 GPa. After friction tests, the morphology of the wear track were analyzed by a MicroXAM3D non-contact surface profiler (AD Corporation, Cambridge, MA, USA). The wear rates $(K)$ after the sliding tests were calculated via equation of $K=V /(F S)$, where $V$ is the wear volume loss $\left(\mathrm{mm}^{3}\right), F$ is normal load $(\mathrm{N})$, and $S$ is total sliding distance $(\mathrm{m})$. Raman signals for the wear track and the counterpart surface were also detected by a Horiba LabRAM HR Evolution spectrometer (Paris, France) with an excitation light source of wavelength $532 \mathrm{~nm}$.

\section{Results and Discussion}

The high-resolution surface scanning electron microscope (SEM) images of the sputtered $\mathrm{WS}_{2}$ films deposited under different substrate temperatures are shown in Figure 1. It can be seen that all the $\mathrm{WS}_{2}$ films generally showed an acicular-like surface with curly columnar platelets. Typically, the sputtered $\mathrm{WS}_{2}$ or $\mathrm{MoS}_{2}$ films deposited at room temperature or high temperature exhibited a columnar plate Zone 2 morphology (Thornton model), which showed inherent porosity, as reported in other literatures $[27,32]$. It can be seen that the $\mathrm{WS}_{2}$ film deposited at room temperature exhibited a loose coarse columnar structure as shown in Figure 1d, similarly to the films investigated by other researchers. While for the film deposited at lower temperatures, a much denser surface was occurred. The width of each columnar plate showed an increase with the increase of the substrate temperature. The mean widths for each of the columnar plate of the deposited $\mathrm{WS}_{2}$ films were 180, 330, 380 and $650 \mathrm{~nm}$ for the films deposited at initial temperature of $-40,-25,0$ and $20{ }^{\circ} \mathrm{C}$, respectively. The featured porous structure of the sputtered $\mathrm{WS}_{2}$ film could be greatly suppressed and a more compact structure would be achieved at the lower deposition temperature due to the change of the nucleation during film growth [30].

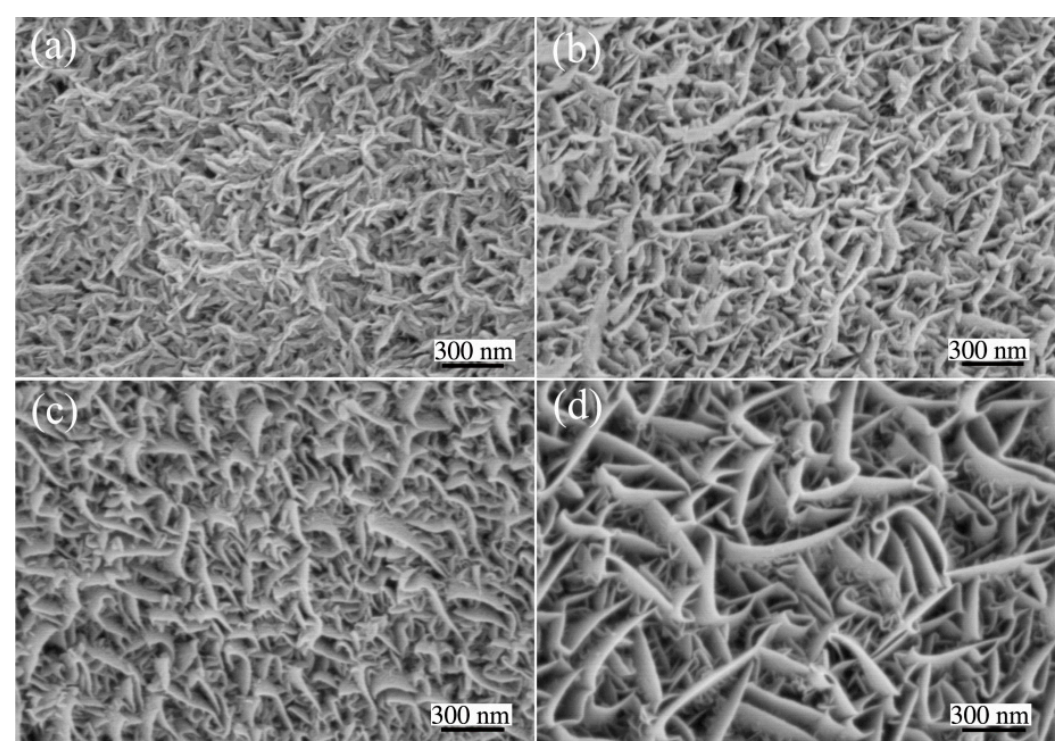

Figure 1. Surface scanning electron microscope (SEM) images of the $\mathrm{WS}_{2}$ films deposited at different substrate temperature: (a) $\mathrm{WS}_{2}-40$; (b) $\mathrm{WS}_{2}-25$; (c) $\mathrm{WS}_{2}-0$; and (d) $\mathrm{WS}_{2}-\mathrm{RT}$.

The integral and high-resolution cross-sectional SEM images of $W_{2}$ film deposited at temperature of $-40{ }^{\circ} \mathrm{C}$ are shown in Figure 2a,b, while that of $\mathrm{WS}_{2}$ film deposited at room temperature is shown in Figure 2c,d. The thickness of the deposited film was controlled to be about $2.2 \mu \mathrm{m}$. It can be seen that the $\mathrm{WS}_{2}$ film exhibited an obvious duplex layer microstructure composed of a very dense layer (approximately $200 \mathrm{~nm}$ ) near the substrate and a columnar platelet one above for the 
$\mathrm{WS}_{2}$ film deposited either at low temperature or at room temperature. However, the upper columnar layers differed greatly under the influence of the substrate temperature. When the film deposited at initial substrate temperature of $20^{\circ} \mathrm{C}$, the columnar layers of the deposited $\mathrm{WS}_{2}$ exhibited a cluster of almost independent coarse columnar plates with a large porosity among the plates. While for the film deposited at initial substrate temperature of $-40{ }^{\circ} \mathrm{C}$, the columnar layers showed a more compact structure with the columnar plates tightly connected with each other, and thus possess a minor porosity compared to the $\mathrm{WS}_{2}$ film deposited at room temperature.

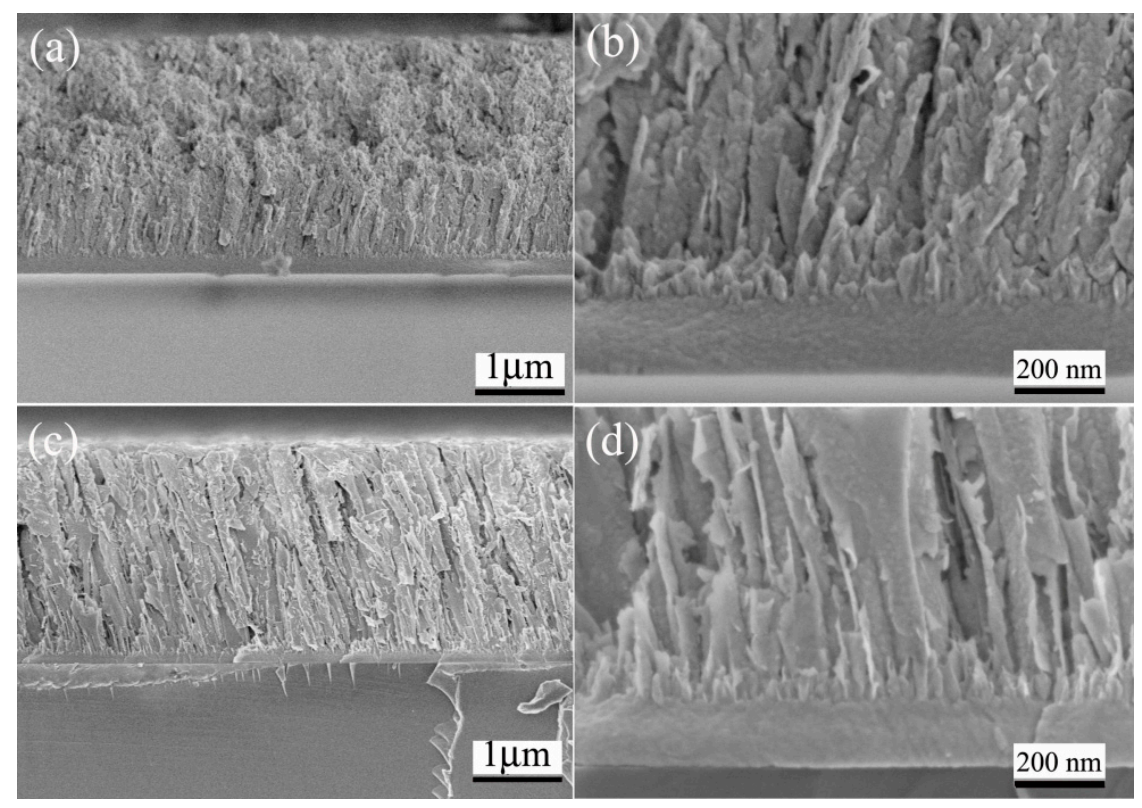

Figure 2. The cross-sectional SEM images under different magnifications for $(\mathbf{a}, \mathbf{b}) \mathrm{WS}_{2}-40$ film and (c,d) $\mathrm{WS}_{2}$-RT films.

Figure 3 shows the $\mathrm{X}$-ray diffraction (XRD) spectra of the $\mathrm{WS}_{2}$ films deposited at different substrate temperatures. The as-deposited $\mathrm{WS}_{2}$ films exhibited hcp-WS $\mathrm{WS}_{2}$ (002), (101), (103), and (112) diffraction peaks $[27,33]$. All the $\mathrm{WS}_{2}$ films are crystalline with a predominantly $(101)$ texture combined along with different intensity of (002), (103) and other diffraction peaks. Generally, the $\mathrm{WS}_{2}$ film deposited at low temperature of $-40{ }^{\circ} \mathrm{C}$ exhibited remarkable (002) peaks and a weak (103) peak. With the initial substrate temperature increased from -40 to $20^{\circ} \mathrm{C}$, the intensity of (002) peak gradually became weaker and weaker and nearly difficult to detect while the intensity of (103) peak increased drastically. Meanwhile, the intensity of the (101) peak was much higher for $\mathrm{WS}_{2}$ film deposited at lower temperature. The XRD results indicated that the crystalline features of the $\mathrm{WS}_{2}$ films were different with the substrate temperature during film deposition.

To further elucidate the effect of the substrate temperature on the microstructure of the deposited $\mathrm{WS}_{2}$ films, the cross-sectional TEM images were performed and typical results for $\mathrm{WS}_{2}-40$ and $\mathrm{WS}_{2}-\mathrm{RT}$ films are shown in Figure 4. The overview TEM images of the Focused ion beam (FIB)-prepared slice showed that a much compact structure for the $\mathrm{WS}_{2}-40$ film while a much loose structure for the $\mathrm{WS}_{2}-\mathrm{RT}$ film, corresponding to the results derived from the SEM. For the $\mathrm{WS}_{2}$ film deposited at room temperature, the initial growth of the $\mathrm{WS}_{2}$ showed a crystalline structure with (002) basal domains with both c-axis orientated parallel and perpendicular to the substrate as shown in Figure 4a2. However, the top layer of the $\mathrm{WS}_{2}$ exhibited a dominant (002) plane with $d$-spacing about $0.66 \mathrm{~nm}$ and the basal plane was perpendicular to the substrate surface, indicating a Type I structure $[17,32]$. For the $\mathrm{WS}_{2}$ film deposited at low temperature of $-40{ }^{\circ} \mathrm{C}$, the region near the substrate showed a main amorphous phase with some crystalline $\mathrm{WS}_{2}$ grains as can be seen from Figure $4 \mathrm{~b} 2$. It was further determined from a selected area electron diffraction (SAED) pattern with rings that are somewhat diffuse. The top layer of the $\mathrm{WS}_{2}-40$ film exhibited a well-crystallized structure as can be determined from both the 
TEM image and the SAED pattern in Figure $4 \mathrm{~b} 2$. It can be seen that the (002) crystalline plane was much more paralleled to the substrate for the $\mathrm{WS}_{2}-40$ film compared to the $\mathrm{WS}_{2}-\mathrm{RT}$. Thus, the detected intensity of (002) peak from the XRD decreased while the intensity of the (103) peak increased with the increase of the deposition temperature for the $\mathrm{WS}_{2}$ films due to the change of the direction of the (002) crystalline plane. The larger intensity of (101) for the $\mathrm{WS}_{2}-25$ and $\mathrm{WS}_{2}-40$ was mainly attributed to the much more compact structure.

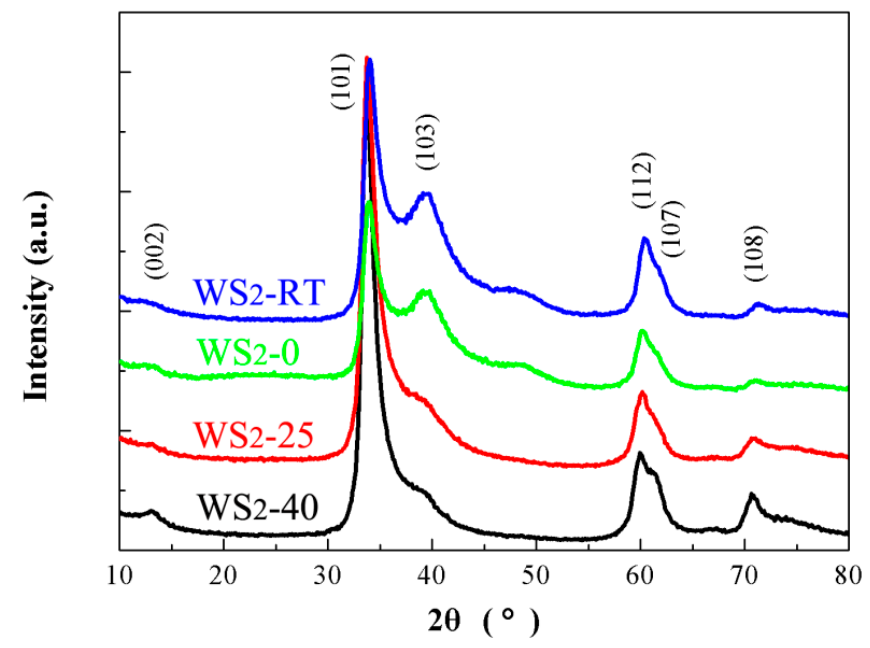

Figure 3. X-ray diffraction (XRD) patterns of the sputtered $\mathrm{WS}_{2}$ films deposited at different substrate temperature: $\mathrm{WS}_{2}-40 ; \mathrm{WS}_{2}-25 ; \mathrm{WS}_{2}-0$; and $\mathrm{WS}_{2}-\mathrm{RT}$.

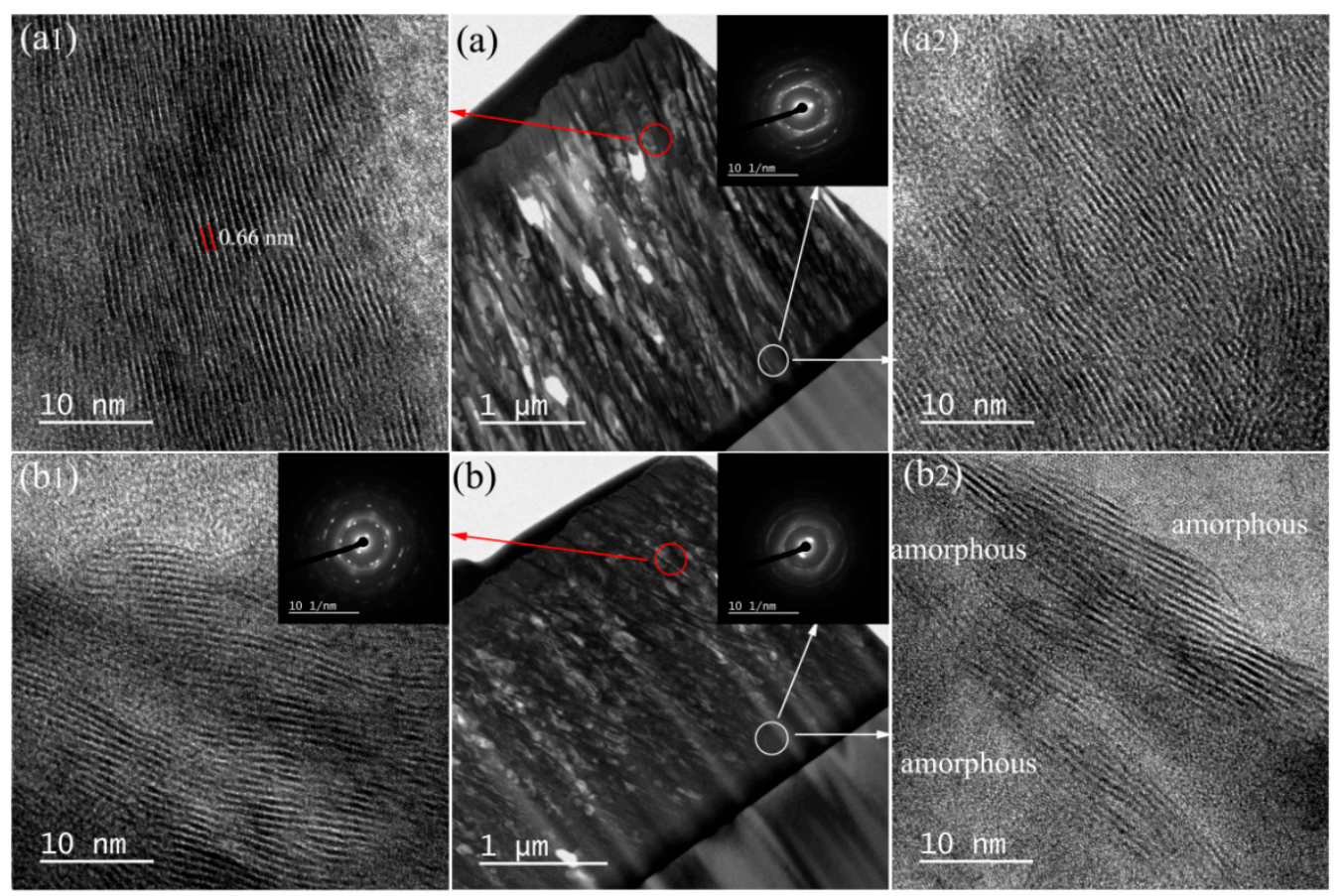

Figure 4. The cross-sectional high-resolution transmission electron microscope (HRTEM) images of $\mathrm{WS}_{2}$ film: $(\mathbf{a}, \mathbf{a} 1, \mathbf{a} 2)$ an overview of FIB-prepared slice of the $\mathrm{WS}_{2}-\mathrm{RT}$ and the magnified image of the selected regions; $(\mathbf{b}, \mathbf{b} \mathbf{1}, \mathbf{b} 2)$ an overview of FIB-prepared slice of the $\mathrm{WS}_{2}-40$ and the magnified image of the selected regions. The insets are the selected area electron diffraction (SAED) pattern of the marked area. 
The typical friction coefficients of the $\mathrm{WS}_{2}$ films deposited at different substrate temperatures are shown in Figure 5. The tribotest was stopped when the friction coefficient of the film reached to 0.2 due to the film failure. In general, it showed that the wear life of the $\mathrm{WS}_{2}$ film exhibited a significant increase with the decrease of the initial substrate temperature. The $\mathrm{WS}_{2}$ film deposited at room temperature showed a limited wear life less than $1.5 \times 10^{5}$ sliding cycles. With the substrate temperature decrease to $0{ }^{\circ} \mathrm{C}$, the changes of the fiction coefficients was similar to that of $\mathrm{WS}_{2}-\mathrm{RT}$, exhibiting a low and minor fluctuating friction coefficient in the initial cycles and then an increased and much fluctuating friction coefficient until the film failure. The wear life of the $\mathrm{WS}_{2}-0$ film was limited to about $2.5 \times 10^{5}$ sliding cycles. When the substrate temperature was set to a lower value of -40 and $-25{ }^{\circ} \mathrm{C}$, the prepared $\mathrm{WS}_{2}$ films exhibited much improved tribological performances. The friction coefficients showed a minor fluctuate with a low mean value below 0.03 in the initial $1.0 \times 10^{5}$ sliding cycles. Afterward, the friction coefficient showed a much minor fluctuation and gradually increased to a higher value about 0.07 . For both $\mathrm{WS}_{2}-25$ and $\mathrm{WS}_{2}-40$ films, the wear lives were higher than $5.0 \times 10^{5}$ sliding cycles.

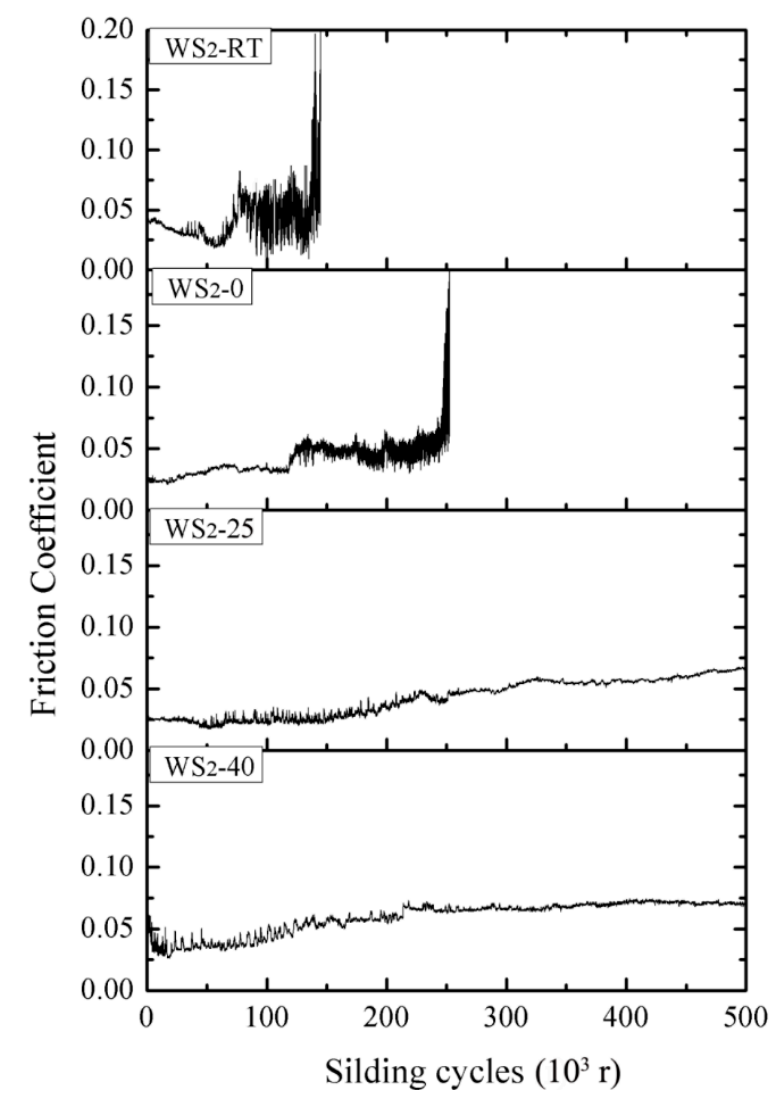

Figure 5. Typical friction curves of the $\mathrm{WS}_{2}$ films deposited at different substrate temperatures.

In order to deeply understand the wear mechanism of the $\mathrm{WS}_{2}$ films deposited at different temperatures, the 3D profile images of the wear track for the $\mathrm{WS}_{2}$ films after $1.0 \times 10^{5}$ sliding cycles were detected and shown in Figure 6. It can be seen that a most narrow and shallow wear track was appeared for the $\mathrm{WS}_{2}-40$ films. While with the increase with the substrate temperature, the wear track of prepared $\mathrm{WS}_{2}$ film exhibited a much more depth with the increase of the substrate temperature. The calculated wear rates were $0.23 \times 10^{-6}, 0.40 \times 10^{-6}, 0.44 \times 10^{-6}$ and $1.35 \times 10^{-6} \mathrm{~mm}^{3} \mathrm{~N}^{-1} \mathrm{~m}^{-1}$ for the $\mathrm{WS}_{2}-40, \mathrm{WS}_{2}-25, \mathrm{WS}_{2}-0$ and $\mathrm{WS}_{2}-\mathrm{RT}$, respectively. Obviously, the wear rate for the $\mathrm{WS}_{2}$ films increased when raising the substrate temperature. 
The Raman spectra at the center of the wear track and the transform layer on the counterpart after $1.0 \times 10^{5}$ sliding cycles and the end of the tribotest were detected as shown in Figure 7. It can be seen that Raman modes with peaks centered at 347, 420 and $524 \mathrm{~cm}^{-1}$ for $\mathrm{E}_{2 \mathrm{~g}}, \mathrm{~A}_{1 \mathrm{~g}}$ and second order Raman modes of $\mathrm{WS}_{2}[33,34]$, respectively, were detected after $1.0 \times 10^{5}$ liding cycles from the wear track for both $\mathrm{WS}_{2}-40$ and $\mathrm{WS}_{2}-\mathrm{RT}$ films, indicating that the films were not worn out. However, the intensity of the Raman signal of the transform layer on the counterpart for the $\mathrm{WS}_{2}-\mathrm{RT}$ was much lower than that of $\mathrm{WS}_{2}-40$. Afterward, the friction coefficient of the $\mathrm{WS}_{2}-\mathrm{RT}$ increased to above 0.05 and fluctuated drastically until film lubricating failure for $1.0 \times 10^{5}$ sliding cycles as shown in Figure 5 . In contrast, well-formed transform layer on the counterpart ball after $1.0 \times 10^{5}$ or $5.0 \times 10^{5}$ sliding cycles was detected by the Raman spectra for the $\mathrm{WS}_{2}-40$ as can be seen in Figure $7 \mathrm{~b}$, indicating a superior lubricating state corresponding to the stable friction curves shown in Figure 5.
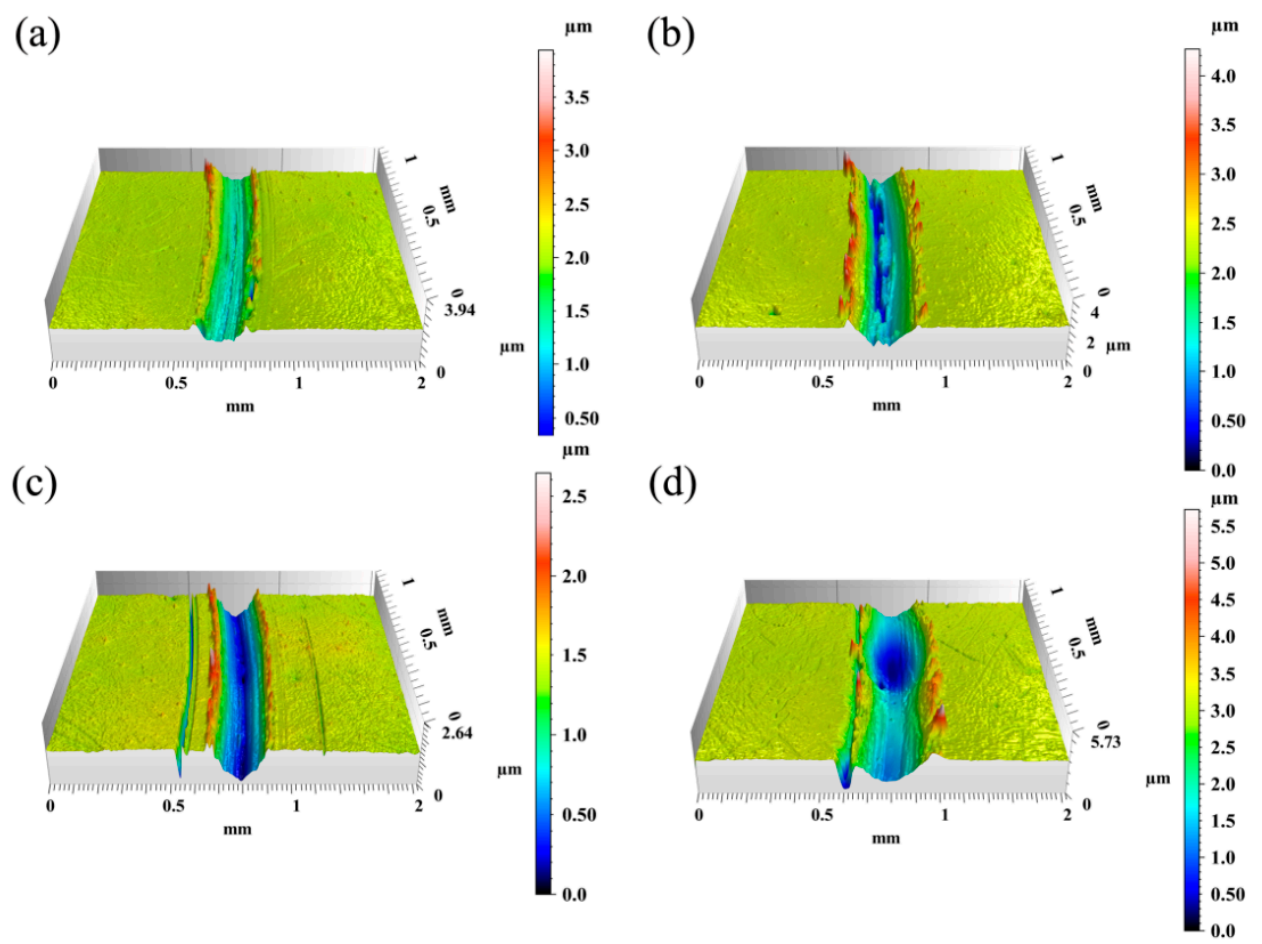

Figure 6. Typical 3D profile images of the wear tracks after sliding $1.0 \times 10^{5}$ cycles in vacuum for (a) $\mathrm{WS}_{2}-40$, (b) $\mathrm{WS}_{2}-25$, (c) $\mathrm{WS}_{2}-0$, and (d) $\mathrm{WS}_{2}-\mathrm{RT}$.
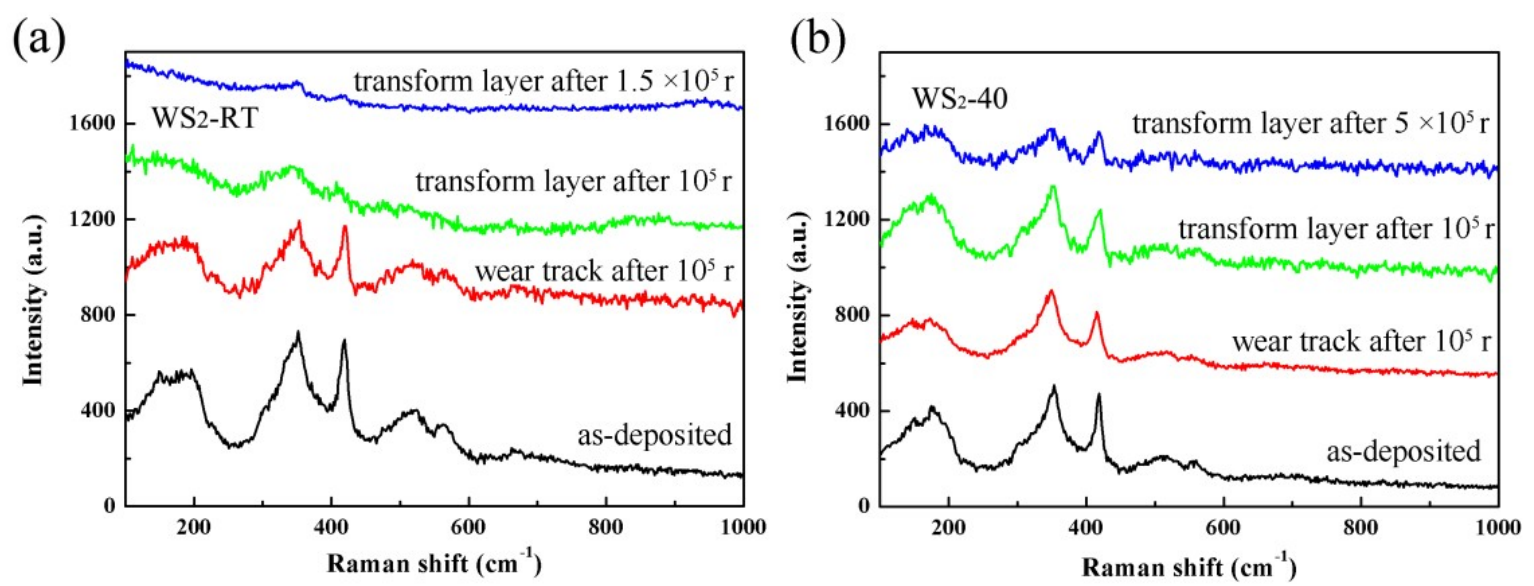

Figure 7. Raman spectra of the as-deposited film, wear track and transform layer on counterpart ball after1.0 $\times 10^{5}$ sliding cycles as well as after film failure or $5.0 \times 10^{5}$ sliding cycles for $(\mathbf{a}) \mathrm{WS}_{2}$-RT and (b) $\mathrm{WS}_{2}-40$ films. 
Finally, pure $\mathrm{WS}_{2}$ films with different microstructures have been prepared by the sputtering technology through adjusting the initial substrate temperature cooled by the liquid nitrogen. With the substrate temperature decreasing from room temperature to $-40{ }^{\circ} \mathrm{C}$, the morphology of the deposited film gradually changed from loose and coarse columnar structure to a much more compact tiny columnar structure, which generally corresponded to the columnar plate Zone 2 morphology. Although the substrate temperature increased due to the ion bombardment during film deposition, the film deposited at lower initial substrate temperature continued the original compact structure. However, changes of the crystallinity along the film thickness were different for the low temperature-deposited film. The $\mathrm{WS}_{2}-40$ film changed from a predominant amorphous structure at the bottom layer to a mainly well crystallized structure at the top layer while the $\mathrm{WS}_{2}$ film deposited at room temperature exhibited a high crystallinity through the whole film as can be seen from Figure 4.

For the pure $\mathrm{WS}_{2}$ thin film with loose columnar plate morphology deposited at room temperature, the occurrence of the deformation/fracture of the columnar plates would happen and only partly rearrangement of the fragmentized plates contributed as an effective lubricating layer to provide low friction coefficient during the sliding friction $[24,35]$. Thus the $\mathrm{WS}_{2}-\mathrm{RT}$ exhibited a higher wear rate and a limited wear life. While for the $\mathrm{WS}_{2}$ film deposited at lower initial substrate temperature of $-40{ }^{\circ} \mathrm{C}$, the much more compact structure could largely suppress the fracture of the tiny columnar of $\mathrm{WS}_{2}$ and resulted in a much lower wear rate nearly one sixth of that for $\mathrm{WS}_{2}-\mathrm{RT}$. The transform lubricating $\mathrm{WS}_{2}$ layer on the counterpart ball plays a great role on the tribological property of the $\mathrm{WS}_{2}$ film $[36,37]$. Compared to the $\mathrm{WS}_{2}$ film deposited at room temperature, the well-ordered transform lubricating $\mathrm{WS}_{2}$ layer would form on the counterpart ball for the $\mathrm{WS}_{2}$ film deposited at lower initial substrate temperature of $-40{ }^{\circ} \mathrm{C}$, as shown in Figure 7. For the $\mathrm{WS}_{2}$ film deposited at room temperature, the (002) crystalline plane totally perpendicular to the substrate as well as the drastic fracture of the columnar plates would be adverse for the formation of the transform lubricating layer. While for the $\mathrm{WS}_{2}$ film deposited at low temperature, both the compact structure and much more paralleled (002) crystalline plane to the substrate, compared to the $\mathrm{WS}_{2}-\mathrm{RT}$, was beneficial for the transforming of the lubricating layer onto the counterpart ball and further maintaining a better lubricating state and a less-fluctuant friction coefficient. Due to the low crystalliinity of the bottom layer, the friction coefficient of the $\mathrm{WS}_{2}-40$ film showed a gradual increase to about 0.07 after $5.0 \times 10^{5}$ sliding cycles, still maintaining a good lubricating state, which is mainly attributed to the well-formed sustained transform layer as detected by the Raman spectrum.

\section{Conclusions}

In summary, pure $\mathrm{WS}_{2}$ films were prepared by radio frequency sputtering technology by controlling the initial substrate temperature from room temperature to $-40{ }^{\circ} \mathrm{C}$. This showed that the initial substrate temperatures have a great influence on the microstructure and tribological property of the prepared films. With decreasing the substrate temperature from room temperature to $-40{ }^{\circ} \mathrm{C}$, the prepared $\mathrm{WS}_{2}$ film changed from the loose and coarse columnar plate structure to a much more compact morphology. The wear rates of the deposited $\mathrm{WS}_{2}$ films showed a great reduction with decreasing substrate temperature. $\mathrm{WS}_{2}$ film deposited at $-40{ }^{\circ} \mathrm{C}$ exhibited a lowest wear rate of $0.23 \times 10^{-6} \mathrm{~mm}^{3} \mathrm{~N}^{-1} \mathrm{~m}^{-1}$, nearly one sixth of that for $\mathrm{WS}_{2}$ film obtained at room temperature. The $\mathrm{WS}_{2}$ film deposited at low temperature of -40 or $-20^{\circ} \mathrm{C}$ exhibited a long wear life higher than $5.0 \times 10^{5}$ sliding cycles while this was only $1.5 \times 10^{5}$ sliding cycles for the $\mathrm{WS}_{2}$ deposited at room temperature. Both the compact structure resulted in a lower wear rate and the sustained formed transform layer on the counterpart ball contributed to the improved tribological properties for the low temperature-deposited $\mathrm{WS}_{2}$ films. 
Author Contributions: Conceptualization, D.W. and X.G.; Formal Analysis, Y.D., Y.W., and Y.F.; Methodology, M.H., Y.D., D.W., and D.J.; Supervision, L.W., and J.S.; Validation, J.S. and X.G.; Writing-Original Draft, M.H. and D.W.; Writing-Review and Editing, D.W. and X.G.

Funding: This research was financially supported by the National Natural Science Foundation of China (Nos. 51575508, 51575509 and 51875551).

Conflicts of Interest: The authors declare no conflict of interest.

\section{References}

1. Banerjee, T.; Chattopadhyay, A. Influence of substrate bias on structural and tribo-mechanical properties of pulsed magnetron sputtered TiN-WS ${ }_{x}$ hard-lubricious coating. Tribol. Int. 2018, 123, 81-91. [CrossRef]

2. Luo, T.; Wang, P.; Qiu, Z.; Yang, S.; Zeng, H.; Cao, B. Smooth and solid $\mathrm{WS}_{2}$ submicrospheres grown by a new laser fragmentation and reshaping process with enhanced tribological properties. Chem. Commun. 2016, 52, 10147-10150. [CrossRef] [PubMed]

3. Scharf, T.; Prasad, S.; Dugger, M.; Kotula, P.; Goeke, R.; Grubbs, R. Growth, structure, and tribological behavior of atomic layer-deposited tungsten disulphide solid lubricant coatings with applications to MEMS. Acta Mater. 2006, 54, 4731-4743. [CrossRef]

4. Zeng, Y.; He, F.; Wang, Q.; Yan, X.; Xie, G. Friction and wear behaviors of molybdenum disulfide nanosheets under normal electric field. Appl. Surf. Sci. 2018, 455, 527-532. [CrossRef]

5. Scharf, T.W.; Prasad, S.V. Solid lubricants: A review. J. Mater. Sci. 2013, 48, 511-531. [CrossRef]

6. Bulbul, F.; Efeoğlu, I.; Arslan, E.; Efeoglu, I. The effect of bias voltage and working pressure on S/Mo ratio at $\mathrm{MoS}_{2}$-Ti composite films. Appl. Surf. Sci. 2007, 253, 4415-4419. [CrossRef]

7. Shi, J.P.; Tong, R.; Zhou, X.B.; Gong, Y.; Zhang, Z.P.; Ji, Q.Q.; Zhang, Y.; Fang, Q.Y.; Gu, L.; Wang, X.N.; et al. Temperature-mediated selective growth of $\mathrm{MoS}_{2} / \mathrm{WS}_{2}$ and $\mathrm{WS}_{2} / \mathrm{MoS}_{2}$ vertical stacks on Au foils for direct photocatalytic applications. Adv. Mater. 2016, 28, 10664. [CrossRef]

8. Arslan, E.; Totik, Y.; Efeoglu, I. Comparison of structure and tribological properties of MoS ${ }_{2}-\mathrm{Ti}$ films deposited by biased-dc and pulsed-dc. Prog. Org. Coat. 2012, 74, 772-776. [CrossRef]

9. Gustavsson, F.; Jacobson, S.; Cavaleiro, A.; Polcar, T. Ultra-low friction W-S-N solid lubricant coating. Surf. Coat. Technol. 2013, 232, 541-548. [CrossRef]

10. Polcar, T.; Gustavsson, F.; Thersleff, T.; Jacobson, S.; Cavaleiro, A. Complex frictional analysis of self-lubricant W-S-C/Cr coating. Faraday Discuss. 2012, 156, 383-401. [CrossRef] [PubMed]

11. Xu, S.; Sun, J.; Weng, L.; Hua, Y.; Liu, W.; Neville, A.; Hu, M.; Gao, X. In-situ friction and wear responses of WS2 films to space environment: Vacuum and atomic oxygen. Appl. Surf. Sci. 2018, 447, 368-373. [CrossRef]

12. Singh, H.; Mutyala, K.C.; Mohseni, H.; Scharf, T.W.; Evans, R.D.; Doll, G.L. Tribological performance and coating characteristics of sputter deposited Ti doped $\mathrm{MoS}_{2}$ in rolling and sliding contact. Tribol. Trans. 2015, 58, 767-777. [CrossRef]

13. Hsu, K.W.; Zhu, Y.; Yao, N.; Firth, S.; Clark, R.; Kroto, H.W.; Walton, D. Titanium-doped molybdenum disulfide nanostructures. Adv. Funct. Mater. 2001, 11, 69-74. [CrossRef]

14. Strapasson, G.; Badin, P.C.; Soares, G.V.; Machado, G.; Figueroa, C.A.; Hubler, R.; Gasparin, A.L.; Baumvol, I.J.R.; Aguzzoli, C.; Tentardini, E.K. Structure, composition, and mechanical characterization of dc sputtered TiN-MoS 2 nanocomposite thin films. Surf. Coat. Technol. 2011, 205, 3810-3815. [CrossRef]

15. Scharf, T.; Kotula, P.; Prasad, S.; Kotula, P. Friction and wear mechanisms in $\mathrm{MoS}_{2} / \mathrm{Sb}_{2} \mathrm{O}_{3} /$ Au nanocomposite coatings. Acta Mater. 2010, 58, 4100-4109. [CrossRef]

16. Stoyanov, P.; Chromik, R.R.; Goldbaum, D.; Lince, J.R.; Zhang, X. Microtribological performance of Au-MoS and Ti-MoS 2 coatings with varying contact pressure. Tribol. Lett. 2010, 40, 199-211. [CrossRef]

17. Arslan, E.; Bulbul, F.; Alsaran, A.; Çelik, A.; Efeoglu, I. The effect of deposition parameters and Ti content on structural and wear properties of $\mathrm{MoS}_{2}$ Ti coatings. Wear 2005, 259, 814-819. [CrossRef]

18. Lince, J.R. Tribology of Co-sputtered Nanocomposite $\mathrm{Au} / \mathrm{MoS}_{2}$ solid lubricant films over a wide contact stress range. Tribol. Lett. 2004, 17, 419-428. [CrossRef]

19. Shang, K.; Zheng, S.; Ren, S.; Pu, J.; He, D.; Liu, S. Improving the tribological and corrosive properties of $\mathrm{MoS}_{2}$-based coatings by dual-doping and multilayer construction. Appl. Surf. Sci. 2018, 437, $233-244$. [CrossRef] 
20. Hu, J.; Bultman, J.; Zabinski, J. Microstructure and lubrication mechanism of multilayered $\mathrm{MoS}_{2} / \mathrm{Sb}_{2} \mathrm{O}_{3}$ thin films. Tribol. Lett. 2006, 21, 169-174. [CrossRef]

21. Pimentel, J.V.; Polcar, T.; Cavaleiro, A. Structural, mechanical and tribological properties of Mo-S-C solid lubricant coating. Surf. Coat. Technol. 2011, 205, 3274-3279. [CrossRef]

22. Polcar, T.; Cavaleiro, A. Review on self-lubricant transition metal dichalcogenide nanocomposite coatings alloyed with carbon. Surf. Coat. Technol. 2011, 206, 686-695. [CrossRef]

23. Li, S.; Deng, J.; Yan, G.; Zhang, K.; Zhang, G. Microstructure, mechanical properties and tribological performance of TiSiN-WS 2 hard-lubricant coatings. Appl. Surf. Sci. 2014, 309, 209-217. [CrossRef]

24. Wang, D.; Hu, M.; Jiang, D.; Gao, X.; Fu, Y.; Sun, J.; Weng, L. Cabbage-like $\mathrm{WS}_{2} / \mathrm{Ni}$ bilayer thin film for improved tribological property. Surf. Coat. Technol. 2019, 358, 50-56. [CrossRef]

25. Wang, D.; Hu, M.; Gao, X.; Jiang, D.; Fu, Y.; Weng, L.; Sun, J. Tailoring of the interface morphology of $\mathrm{WS}_{2} / \mathrm{CrN}$ bilayered thin film for enhanced tribological property. Vacuum 2018, 156, 157-164. [CrossRef]

26. Arenas, M.A.; Ahuir-Torres, J.I.; García, I.; Carvajal, H.; de Damborenea, J. Tribological behaviour of laser textured Ti6Al4V alloy coated with $\mathrm{MoS}_{2}$ and graphene. Tribol. Int. 2018, 128, 240-247. [CrossRef]

27. Scharf, T.; Rajendran, A.; Banerjee, R.; Sequeda, F. Growth, structure and friction behavior of titanium doped tungsten disulphide (Ti-WS 2 ) nanocomposite thin films. Thin Solid Films 2009, 517, 5666-5675. [CrossRef]

28. Bozheyev, F.; Valiev, D.; Nemkayeva, R. Pulsed cathodoluminescence and Raman spectra of $\mathrm{MoS}_{2}$ and $\mathrm{WS}_{2}$ nanocrystals and their combination $\mathrm{MoS}_{2} / \mathrm{WS}_{2}$ produced by self-propagating high-temperature synthesis. Appl. Phys. Lett. 2016, 108, 093111. [CrossRef]

29. Chen, F.; Wang, L.; Ji, X.; Zhang, Q. Temperature-dependent two-dimensional transition metal dichalcogenide heterostructures: controlled synthesis and their properties. ACS Appl. Mater. Interfaces 2017, 9, 30821-30831. [CrossRef] [PubMed]

30. Spalvins, T. Tribological properties of sputtered $\mathrm{MoS}_{2}$ films in relation to film morphology. Thin Solid Films 1980, 73, 291-297. [CrossRef]

31. Gao, X.; Sun, J.; Fu, Y.; Jiang, D.; Wang, D.; Weng, L.; Hu, M. Improved wear resistance of $\mathrm{WS}_{2}$ film by LT-deposited Ti interlayer with $\omega$ phase structure. Vacuum 2018, 155, 423-427. [CrossRef]

32. Hilton, M.R.; Jayaram, G.; Marks, L.D. Microstructure of cosputter-deposited metal- and oxide-MoS 2 solid lubricant thin films. Tribol. Int. 2011, 13, 1022-1032. [CrossRef]

33. Deepthi, B.; Barshilia, H.C.; Rajam, K.; Konchady, M.S.; Pai, D.M.; Sankar, J. Structural, mechanical and tribological investigations of sputter deposited $\mathrm{CrN}-\mathrm{WS}_{2}$ nanocomposite solid lubricant coatings. Tribol. Int. 2011, 44, 1844-1851. [CrossRef]

34. Perea-López, N.; Elías, A.L.; Berkdemir, A.; Castro-Beltran, A.; Gutiérrez, H.R.; Feng, S.; Lv, R.; Hayashi, T.; López-Urías, F.; Ghosh, S.; et al. Photosensor device based on few-layered $\mathrm{WS}_{2}$ films. Adv. Funct. Mater. 2013, 23, 5511-5517. [CrossRef]

35. Moser, J.; Levy, F. MoS $_{2-x}$ lubricating films: Structure and wear mechanisms investigated by cross-sectional transmission electron microscopy. Thin Solid Films 1993, 228, 257-260. [CrossRef]

36. Spalvins, T. Frictional and morphological properties of $\mathrm{Au}-\mathrm{MoS}_{2}$ films sputtered from a compact target. Thin Solid Films 1984, 118, 375-384. [CrossRef]

37. Zhang, X.; Qiao, L.; Chai, L.; Xu, J.; Shi, L.; Wang, P. Structural, mechanical and tribological properties of Mo-S-N solid lubricant films. Surf. Coat. Technol. 2016, 296, 185-191. [CrossRef]

(C) 2019 by the authors. Licensee MDPI, Basel, Switzerland. This article is an open access article distributed under the terms and conditions of the Creative Commons Attribution (CC BY) license (http://creativecommons.org/licenses/by/4.0/). 